\title{
Tavşan trakeası üzerine levamizolun etkisinin tek başına ve triklorfonla birlikte araştırılması
}

\author{
Ebru YILDIRIM \\ Kırıkkale Üniversitesi Veteriner Fakültesi, Farmakoloji ve Toksikoloji Anabilim Dalı, Kırıkkale.
}

\begin{abstract}
Özet: $\mathrm{Bu}$ araştırmada, levamizolun tavşan trakeası üzerine etkisini belirlemek, levamizolun antagonistlerini saptamak, levamizol ile triklorfon arasındaki ilişkiye açıklık kazandırmak amaçlandı. Levamizol $\left(10^{-8}-10^{-3} \mathrm{M}\right)$ birikimli derişimlerde ve $5 \times 10^{-5}$ M derişimde asetilkolin (Ak), karbakol, betanekol, triklorfon, mekamilamin, nikotin ve atropin ile birlikte değişik terkip ve derişimlerde 82 tavşan trakeası üzerinde çalışıldı. Tavşan trakeası üzerine levamizolun tek başına etkisiz olduğu tespit edildi. Levamizol inkübasyonunun Ak'nın $\mathrm{E}_{\max }$ değerini artırdığı $(\mathrm{p}<0.01)$, karbakolun $\mathrm{pD}_{2}$ yanıtlarını azalttı̆̆ $(\mathrm{p}<0.05)$ ve $\mathrm{E}_{\max }$ değerlerini artırdığ $1(\mathrm{p}<0.05)$, betanekolun ise sadece $\mathrm{pD}_{2}$ değerini azalttığ $(\mathrm{p}<0.05)$ belirlendi. Nikotinin levamizol ile inkübasyon sonucunda kasılma oluşturmadığı saptandı. Sonuçta levamizolun tavşan trakeasındaki etkisinin özellikle muskarinik reseptörler aracılığı ile ortaya çıktığı, bununla birlikte az da olsa nikotinik etkilerinin olduğu, triklorfonla birlikte kullanıldığında istenmeyen etkileri de içerecek şekilde her iki ilacın etkisinin artığı, dolayısı ile birlikte kullanılmaması gerektiği, levamizolle betanekol arasında yarışmalı bir antagonizma olabileceği, levamizol zehirlenmelerinde tek başına gangliyon blokörünün yeterli olmayacağı, bunun yanında atropin kullanılmasının faydalı olacağı görüşüne varıldı.
\end{abstract}

Anahtar sözcükler: Farmakodinamik etki, levamizol, tavşan, trakea, triklorfon.

\section{The investigation of the effect of levamisole on rabbit trachea alone and combined with trichlorfon}

Summary: The aim of this study is to investigate the effect of levamisole on rabbit trachea, the antagonists of levamisole and reveal the relation between trichlorfon and levamisole. The cumulative concentrations of levamisole $\left(10^{-8}-10^{-3} \mathrm{M}\right)$ were applied to the tracheal ring of rabbit. Bethanecole, carbachol, acetylcholine, trichlorfon, mecamylamine, atropine and nicotin were also studied with levamisole. Levamisole was without considerable effect alone on rabbit trachea. It was seen that the incubation with levamisole increased the $\mathrm{E}_{\max }$ value of acetylcholine $(\mathrm{p}<0.01)$, and carbachol $(\mathrm{p}<0.05)$. Incubation with levamisole decreased the $\mathrm{pD}_{2}$ value of carbachol $(\mathrm{p}<0.05)$ and bethanechol $(\mathrm{p}<0.05)$. The temporary muscle contractions of nicotine, were not seen after the incubation with levamisole. It was concluded that the effect of levamisole was elicited mostly via muscarinic receptors. There was also a little nicotinic effect observed. There can be a competetive antogonism between bethanechol and levamisole. The combined use of trichlorfon and levamisole is not recommended. Mecamylamine would not be enough to control the levamisole toxicosis, atropine should also be used as an antidote for levamisole toxicosis.

Key words: Levamisole, pharmacodynamic effect, rabbit, trachea, trichlorfon.

\section{Giriş}

Levamizol, hayvanlarda iç parazitlere karşı kullanılan geniş spektrumlu bir antelmintiktir. Tetramizolun levo izomeridir (22). Levamizol parazitleri felç ederek etkir, nikotin benzeri etki göstererek parazitin otonomik gangliyonlarını uyarır (15). Memelilerde levamizolun hangi mekanizma ile kolinerjik iletimi etkilediği bilinmemektedir. Ancak bulguların çoğu ilacın nikotin benzeri bir etkisinin olduğunu göstermektedir (3). Eyre (8), Hsu (12,13), Cook ve ark. (6) da levamizolun nikotin benzeri etkili bir madde olduğunu belirtmişlerdir. Tetramizol ve levamizolun muskarinik etkilerinin olduğu da bildirilmektedir $(6,8,20)$. Shah ve ark. (19), levamizolun monoaminoksidaz ve katekolamin-o-metiltransferaz etkinliğini önlediğini ileri sürmüşlerdir. Gulati ve ark. (11), levamizolun sinaps sonrasinda $\alpha$ adrenerjik reseptörler üzerine bir etkisi olmadığını belirtmişlerdir. Levamizolun etki mekanizmasiyla ilgili olarak, tetramizol (8) ve levamizolun $(11,19)$ kolinesterazın etkinliğini önlediğini belirten çalışmaların yanı sıra, domuzlarda ve sığırlarda levamizol uygulamasının kan kolinesteraz düzeyinde farklılık yapmadığını gösteren çalışmalar da vardır $(9,13)$. Ayrıca, Caposso ve ark. (5), levamizolun izole kobay bağırsağında prostaglandin $E_{2}$ $\left(\mathrm{PGE}_{2}\right)$ ile oluşturulan kasılmaları artırdığını ve bu etkinin indometasinle önlendiğini göstermişlerdir.

Nikotin benzeri etkisi nedeniyle levamizolun organik fosforlu (OF) bileşiklerle birlikte kullanılması

\footnotetext{
* Aynı başlıklı doktora tezinden özetlenen bu çalışma DPT (2002-K-120130-8 no'lu proje) tarafindan desteklenmiştir.
} 
önerilmemektedir $(7,15)$. Buna karşın, yine birçok kaynakta $(9,10,12,13,17)$ OF bileşiklerle levamizolun birlikte kullanılmasının levamizolun zehirliliğini artırmadığı da gösterilmiştir. Farklı olarak Aldabagh ve Mohammad (2) levamizolun önceden uygulanmasının tavşanları diklorvos zehirlenmesinden koruduğunu tespit etmişlerdir.

$\mathrm{Bu}$ çalışmada, canlılarda etki mekanizması tam olarak anlaşılamayan levamizolun In vitro olarak tavşan trakeasında farmakodinamik etkilerinin değerlendirilmesi ve triklorfonla arasındaki ilişkiye açıklık kazandırılması amaçlanmıştır.

\section{Materyal ve Metot}

Deneylerde 3-5 aylık 1000-2500 g ağırlığında, 53 Yeni Zelanda 1rkı erkek tavşandan sağlanan 82 trakea çalışıldı. Tavşanlar kas içi $50 \mathrm{mg} / \mathrm{kg}$ ketamin, $10 \mathrm{mg} / \mathrm{kg}$ ksilazin uygulaması ile anestezi edildi ve boyun bölgesine lateral ve karın bölgesine doğru dik olarak $\mathrm{T}$ şeklinde kesildi. Trakea, Hulsmann ve De Jongste' nin (14) tanımladığı gibi halka tarzında izole edilip, içinde 10 ml Krebs çözeltisi $\left(37^{\circ} \mathrm{C}\right)$ bulunan izole organ banyosuna $1 \mathrm{~g}$ lık bir ağırlık uygulanarak asıldı, dokulara \%95 oksijen ve $\% 5$ karbondioksit gaz karışımı uygulandı. Krebs-Henseleit çözeltisi (mM): $\mathrm{NaCl}: 118, \mathrm{NaHCO}_{3}$ : 25, Anhidr glikoz: 11.1, $\mathrm{KH}_{2} \mathrm{PO}_{4}: 1.2, \mathrm{KCl}: 4.8$, $\mathrm{Mg}_{2} \mathrm{SO}_{4} \cdot 7 \mathrm{H}_{2} \mathrm{O}: 1.2, \mathrm{CaCl}_{2} .2 \mathrm{H}_{2} \mathrm{O}: 1.2$ (Çözeltinin pH's1 7.4). Kullanılan Kimyasal Maddeler: Levamizol, asetilkolin klorür, nikotin hidrojen tartrat, karbamilkolin klorür, betanekol, triklorfon, mekamilamin, atropin sülfat ve potasyum klorür. Potasyum klorür Merck, diğer kimyasal maddeler ise Sigma ürünüdür.

Doksan dakika (dak.) süre ile dengelenen doku, 15 dak. bir Krebs çözeltisi ile yıkandı. Dengelenme sonrasında dokunun canlılığını tespit etmek için asetilkolin (Ak) $\left(3 \times 10^{-5} \mathrm{M}\right)$ ile kasılması sağlandı. Deneyler sırasındaki gerimdeki değişiklikler izometrik gerim ileticisi (FDT-10A May) aracılığı ile ölçüldü ve bilgisayara kaydedildi. Araştırma için yapılan deney protokolleri Tablo 1 ve 2' de verildi. Levamizolun $5 \times 10^{-5} \mathrm{M}$ derişimi Caposso ve ark (5) dan seçildi. Tablo 1' deki 1-6 protokollerden elde edilen yanıtların değerlendirilmesi, söz

Tablo 1. Tavşan trakeası üzerine levamizolun etkisinin tek başına ve diğer ilaçlarla araştırılması için yapılan deney protokolleri.

Table 1. The experimental protocols to investigate the effect of levamisole alone and combined with other drugs on rabbit trachea.

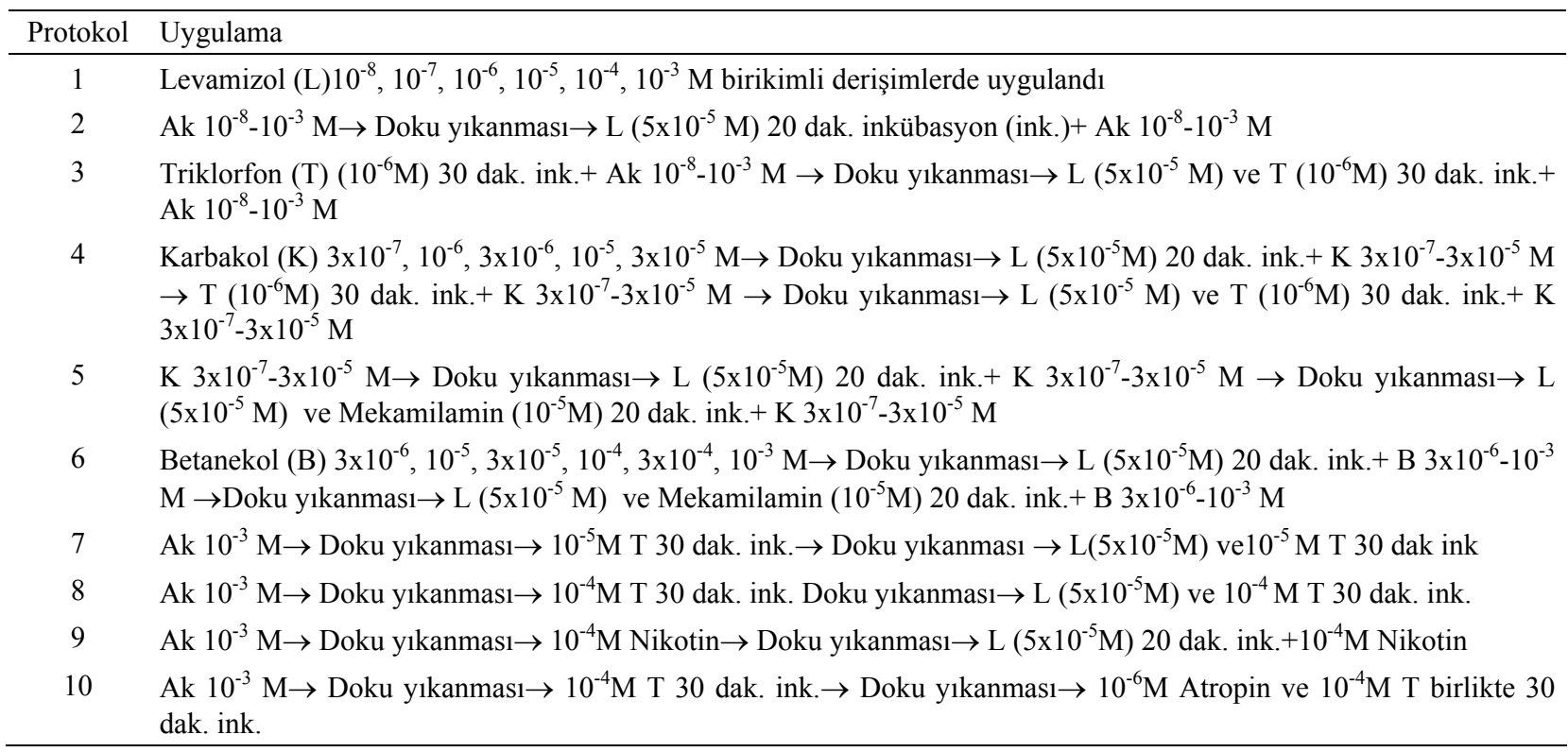

Tablo 2. Kasılma oluşturulmuş tavşan trakeası üzerine levamizolun etkisinin araştırılması için yapılan deney protokolleri Table 2. The experimental protocols to investigate the effect of levamisole on precontracted rabbit trachea

\begin{tabular}{|c|c|}
\hline Protokol & Uygulama \\
\hline 1 & $\mathrm{Ak} \mathrm{EC}_{85}\left(3 \times 10^{-5} \mathrm{M}\right)$ ile kasilma+ L $\left(10^{-8}-10^{-3} \mathrm{M}\right)$ \\
\hline 2 & $\begin{array}{l}\text { Ak EC } \mathrm{EC}_{50}\left(10^{-5} \mathrm{M}\right) \text { ile kasılma+ L }\left(10^{-8}-10^{-3} \mathrm{M}\right) \rightarrow \text { Doku yıkanması } \rightarrow \text { Kontrol amaçlı Ak EC } \mathrm{EC}_{50}\left(10^{-5} \mathrm{M}\right) 10 \text { dak. } \\
\text { boyunca kasılma }\end{array}$ \\
\hline 3 & $\begin{array}{l}\mathrm{K} \mathrm{EC}_{85}\left(1.7 \times 10^{-6} \mathrm{M}\right) \text { ile kasılma }+\mathrm{L}\left(10^{-8}-10^{-3} \mathrm{M}\right) \rightarrow \text { Doku yıkanması } \rightarrow \text { Kontrol amaçlı } \mathrm{K} \mathrm{EC}_{85}\left(1.7 \times 10^{-6} \mathrm{M}\right) 10 \text { dak. } \\
\text { boyunca kasılma }\end{array}$ \\
\hline 4 & $\begin{array}{l}\text { Potasyum klorür }(\mathrm{KCl})(80 \mathrm{mM}) \text { ile kasılma }+\mathrm{L}\left(10^{-8}-10^{-3} \mathrm{M}\right) \rightarrow \text { Doku yıkanması } \rightarrow 10^{-6} \mathrm{M} \text { atropin ile } 20 \text { dak. ink. }+ \\
\mathrm{KCl}(80 \mathrm{mM}) \text { ile kasılma }+\mathrm{L}\left(10^{-8}-10^{-3} \mathrm{M}\right) \rightarrow \text { Doku yıkanması } \rightarrow \text { Kontrol amaçlı } \mathrm{KCl}(80 \mathrm{mM}) 10 \text { dak. boyunca } \\
\text { kasılma }\end{array}$ \\
\hline
\end{tabular}


konusu ilaçların $\mathrm{pD}_{2}$ ve $\mathrm{E}_{\max }$ parametrelerinin karşılaşt1rılması ile yapıldı. $\mathrm{pD}_{2}$ değeri maksimal etkinliğin yarısını oluşturmak için gereken ilaç derişiminin negatif logaritmasıdır ve ilacın reseptöre afinitesini gösterir. $E_{\max }$ değeri ise ilaç tarafindan oluşturulan maksimum etkinliğin \% şeklinde ifadesi olup, ilacın efikasitesini verir (16). Yanıtların $\mathrm{pD}_{2}$ değerleri, ilacın en yüksek yanıtı 100 kabul edilerek, Pharm PCS-Version 4. Pharmacologic calculation paket programı kullanılarak hesaplandi. $\mathrm{E}_{\max }$ ise bazal çizgi 100 kabul edilerek, yanıtta derişime bağlı artışlar ise bazal çizgiye göre \% artış olarak hesaplandı. Tablo 1' deki 7-10 protokollerden alınan yanitlar $\left(\mathrm{E}_{\max }\right)$ $10^{-3} \mathrm{M}$ Ak yanıt1 100 kabul edilerek, yüzde olarak hesaplandı. Tablo 2' deki protokollerden elde edilen yanıtlar, ilk kasılmada oluşan kasılma büyüklüğünün yüzdesi olarak ifade edildi. Ayrıca yanıtların $\mathrm{E}_{\max }$ değerleri de karşılaştırıldı.

İstatistiksel hesaplamalarda "SPSS 11 for Windows" istatistik paket programı kullanıldı. Veriler aritmetik ortalama ve standart hata şeklinde ifade edildi. Karşılaştırılacak ikili gruplar arasında Wilcoxon eşleştirilmiş iki örnek testi kullanıldı. Karşılaştırılacak grup sayısı ikiden fazla olduğunda tekrarlı ölçümlerde Friedman varyans analizi kullanıldı. Önemlilik belirlenmesi durumunda ise Wilcoxon test ile önemliliği oluşturan gruplar belirlendi. Bağımsız gruplarda ise Kruskall Wallis testi yapıldı.

\section{Bulgular}

Levamizol uygulanmasının (n: 8) tavşan trakeası üzerine etki oluşturmadığ 1 görüldü.

Levamizolun, Triklorfon $\left(10^{-6} \mathrm{M}\right)$ ve Ak İle Birlikte Etkisi: Levamizol $\left(5 \times 10^{-5} \mathrm{M}\right)$ ile inkübasyon, $\mathrm{Ak}^{\prime} \mathrm{nin}$ $\mathrm{E}_{\max }$ değerini istatistiksel olarak artırırken $(\mathrm{p}<0.01), \mathrm{pD}_{2}$ değerini değiştirmedi. Triklorfon $\left(10^{-6} \mathrm{M}\right)$ ve levamizol $\left(5 \times 10^{-5} \mathrm{M}\right)$ ile inkübe edilen dokularda, triklorfon $\left(10^{-6}\right.$ $\mathrm{M})$ inkübasyonu yapılmış dokulara göre $\mathrm{Ak}^{\prime}$ nin $\mathrm{pD}_{2}$ ve $\mathrm{E}_{\max }$ değerlerinde de istatistiksel olarak bir artış $(\mathrm{p}<0.01)$ bulundu. Triklorfon ve levamizol inkübasyonu, levamizol inkübasyonu yapılmış dokulara göre $\mathrm{Ak}$ ' nin $\mathrm{pD}_{2}$ değerlerinde artış $(\mathrm{p}<0.01)$ oluştururken, $\mathrm{E}_{\max }$ değerlerinde istatistiksel olarak bir farklılık bulunmadı (Tablo 3).

Triklorfonun $\left(10^{-5} \mathrm{M}\right.$ ve $\left.10^{-4} \mathrm{M}\right)$ Oluşturduğu Kasılmanın Levamizol İle Birlikte Değerlendirilmesi: Triklorfon $\left(10^{-5} \mathrm{M}\right)$ ile 30 dak inkübe edilmiş dokularda, levamizol $\left(5 \times 10^{-5} \mathrm{M}\right)+$ triklorfon $\left(10^{-5} \mathrm{M}\right)$ inkübe edilmiş dokulara göre (T+L: 75.44 \pm 13.74 , T: $56.44 \pm 17.70)$ istatistiksel olarak anlamlı bir fark bulunmadı (n: 9). Triklorfon $\left(10^{-4} \mathrm{M}\right)$ ile 30 dak inkübe edilmiş dokularda ise, triklorfon ve levamizol ile inkübe edilmiş dokularla karşılaştırınca, istatistiksel olarak anlamlı bir azalma $(\mathrm{p}<0.01)$ bulundu (Tablo 4). Atropin $\left(10^{-6} \mathrm{M}\right)$ triklorfonun $\left(10^{-4} \mathrm{M}\right)$ etkisini tamamen önledi (n:5).
Tablo 3. Asetilkolin, asetilkolin+levamizol, triklorfon+ asetilkolin, levamizol+ triklorfon+ asetilkolin $\mathrm{pD}_{2}$ ve $\mathrm{E}_{\max }$ değerleri. Table 3. The $\mathrm{pD}_{2}$ ve $\mathrm{E}_{\max }$ value of acetylcholine, levamisole + acetylcholine, trichlorfon+ acetylcholine, trichlorfon+ levamisole+ acetylcholine.

\begin{tabular}{lcc}
\hline Uygulama & $\mathrm{pD}_{2}$ & $\mathrm{E}_{\max }$ \\
\hline Asetilkolin $\left(10^{-8}-10^{-3} \mathrm{M}\right)(\mathrm{n}: 8)$ & $4.84 \pm 0.13$ & $91.50 \pm 9.79$ \\
Levamizol $\left(5 \times 10^{-5} \mathrm{M}\right)+$ & & $118.13 \pm 10.86$ \\
Asetilkolin $\left(10^{-8}-10^{-3} \mathrm{M}\right)(\mathrm{n}: 8)$ & $4.98 \pm 0.14$ & \\
Önem düzeyi $(\mathrm{p})$ & - & $* *$ \\
$\begin{array}{l}\text { Triklorfon }\left(10^{-6} \mathrm{M}\right)+ \\
\text { Asetilkolin }\left(10^{-8}-10^{-3} \mathrm{M}\right)(\mathrm{n}: 11)\end{array}$ & $5.73 \pm 0.20$ & $95.60 \pm 11.86$ \\
$\begin{array}{l}\text { Triklorfon }\left(10^{-6} \mathrm{M}\right)+ \\
\text { Levamizol }\left(5 \mathrm{X} 10^{-5} \mathrm{M}\right)+\end{array}$ & & \\
$\begin{array}{l}\text { Asetilkolin }\left(10^{-8}-10^{-3} \mathrm{M}\right)(\mathrm{n}: 11) \\
\text { Önem düzeyi }(\mathrm{p})\end{array}$ & $* .41 \pm 0.15$ & $118.90 \pm 14.70$ \\
$\begin{array}{l}\mathrm{L}+\text { Ak ile } \mathrm{T}+\mathrm{L}+\mathrm{Ak} \text { arasındaki } \\
\text { önem düzeyi }(\mathrm{p})\end{array}$ & $* *$ & $* *$ \\
$\begin{array}{l}\text { Ak ile T+Ak arasindaki önem } \\
\text { düzeyi (p) }\end{array}$ & $* *$ & - \\
\hline
\end{tabular}

- : önemsiz

$* *: \mathrm{p}<0.01$

Tablo 4. Triklorfon $\left(10^{-4} \mathrm{M}\right)$, triklorfon $\left(10^{-4} \mathrm{M}\right)$ +levamizol $\left(5 \times 10^{-5} \mathrm{M}\right) \mathrm{E}_{\max }$ sonuçları

Table 4. $\mathrm{E}_{\max }$ value of trichlorfon $\left(10^{-4} \mathrm{M}\right)$, trichlorfon $\left(10^{-4} \mathrm{M}\right)$ + levamisole $\left(5 \times 10^{-5} \mathrm{M}\right)$

\begin{tabular}{lc}
\hline Uygulama (n: 8) & $\mathrm{E}_{\max }$ \\
\hline Triklorfon $10^{-4} \mathrm{M}$ & $121.38 \pm 12.01$ \\
Triklorfon $10^{-4} \mathrm{M}+$ Levamizol $5 \times 10^{-5} \mathrm{M}$ & $71.75 \pm 12.96$ \\
Önem düzeyi $(\mathrm{p})$ & $* *$ \\
\hline$* * \quad: \mathrm{p}<0.01)$ &
\end{tabular}

Tablo 5. Karbakol, karbakol+levamizol, karbakol+triklorfon, karbakol+triklorfon+levamizol $\mathrm{pD}_{2}$ ve $\mathrm{E}_{\max }$ değerleri.

Table 5.The $\mathrm{pD}_{2}$ ve $\mathrm{E}_{\max }$ value of carbachol, levamisole+ carbachol, trichlorfon+ carbachol, trichlorfon+ levamisole+ carbachol

\begin{tabular}{lcc}
\hline Uygulama (n: 6) & $\mathrm{pD}_{2}$ & $\mathrm{E}_{\max }$ \\
\hline Karbakol $\left(3 \times 10^{7}-3 \times 10^{-5}\right)$ & $6.27 \pm 0.11^{\mathrm{a}}$ & $124.17 \pm 15.25^{\mathrm{a}}$ \\
Levamizol $\left(5 \times 10^{-5} \mathrm{M}\right)+$ & & \\
Karbakol $\left(3 \times 10^{7}-3 \times 10^{-5}\right)$ & $5.98 \pm 0.02^{\mathrm{b}}$ & $150.17 \pm 24.63^{\mathrm{b}}$ \\
Triklorfon $\left(10^{-6} \mathrm{M}\right)+$ & & \\
Karbakol $\left(3 \times 10^{-7}-3 \times 10^{-5} \mathrm{M}\right)$ & $6.01 \pm 0.04^{\mathrm{ab}}$ & $154.33 \pm 23.37^{\mathrm{b}}$ \\
Levamizol $\left(5 \times 10^{-5} \mathrm{M}\right)+$ & & \\
Triklorfon $\left(10^{-6} \mathrm{M}\right)+$ & $5.81 \pm 0.07^{\mathrm{c}}$ & $154.17 \pm 22.97^{\mathrm{b}}$ \\
Karbakol $\left(3 \times 10^{-7}-3 \times 10^{-5} \mathrm{M}\right)$ & & \\
Önem düzeyi $(\mathrm{p})$ & $*$ & $*$ \\
\hline * $\quad$ p $<0.05$ & & \\
abc Aynı sütunda farklı harfleri taşıyan gruplar arasındaki fark \\
$\quad$ önemlidir.
\end{tabular}


Tablo 6. Karbakol, karbakol+levamizol, karbakol+levamizol+ mekamilamin $\mathrm{pD}_{2}$ ve $\mathrm{E}_{\max }$ değerleri.

Table 6. $\mathrm{pD}_{2}$ ve $\mathrm{E}_{\max }$ value of carbachol, carbachol+levamisole, carbachol+levamisole+mecamylamine

\begin{tabular}{lcc}
\hline Uygulama (n: 6) & $\mathrm{pD}_{2}$ & $\mathrm{E}_{\max }$ \\
\hline Karbakol $\left(3 \times 10^{7}-3 \times 10^{-5}\right)$ & $6.23 \pm 0.19^{\mathrm{a}}$ & $133.00 \pm 12.82^{\mathrm{a}}$ \\
Levamizol $\left(5 \times 10^{-5} \mathrm{M}\right)+$ & $5.92 \pm 0.10^{\mathrm{b}}$ & $156.83 \pm 13.09^{\mathrm{b}}$ \\
Karbakol $\left(3 \times 10^{7}-3 \times 10^{-5}\right)$ & & \\
Levamizol $\left(5 \times 10^{-5} \mathrm{M}\right)+$ & & \\
Karbakol $\left(3 \times 10^{7}-3 \times 10^{-5}\right)+$ & $5.77 \pm 0.09^{\mathrm{c}}$ & $171.83 \pm 12.48^{\mathrm{c}}$ \\
Mekamilamin $\left(10^{-5}\right)$ & & $*$ \\
Önem düzeyi $(\mathrm{p})$ & $*$ & \\
\hline$*$ : $<0.05$ & & \\
abc Aynı sütunda farklı harfleri taşıyan gruplar arasındaki fark \\
$\quad$ önemlidir .
\end{tabular}

Tablo 7. Betanekol, betanekol+levamizol, betanekol+levamizol+mekamilamin $\mathrm{pD}_{2}$ ve $\mathrm{E}_{\max }$ değerleri.

Table 7. $\mathrm{pD}_{2}$ ve $\mathrm{E}_{\max }$ value of bethanechol, bethanechol+ levamisole, bethanechol+ levamisole+ mecamylamine

\begin{tabular}{|c|c|c|}
\hline Uygulama (n: 7) & $\mathrm{pD}_{2}$ & $E_{\max }$ \\
\hline Betanekol $\left(3 \times 10^{-6}-10^{-3} \mathrm{M}\right)$ & $4.33 \pm 0.07^{\mathrm{a}}$ & $130.86 \pm 14.98$ \\
\hline $\begin{array}{l}\text { Levamizol }\left(5 \times 10^{-5} \mathrm{M}\right) \\
\text { Betanekol }\left(3 \times 10^{-6}-10^{-3} \mathrm{M}\right)\end{array}+$ & $4.15 \pm 0.04^{\mathrm{b}}$ & $147.43 \pm 18.78$ \\
\hline $\begin{array}{l}\text { Levamizol }\left(5 \times 10^{-5} \mathrm{M}\right)+ \\
\text { Betanekol }\left(3 \times 10^{-6}-10^{-3} \mathrm{M}\right)+ \\
\text { Mekamilamin }\left(10^{-5} \mathrm{M}\right)\end{array}$ & $4.15 \pm 0.03^{b}$ & $148.43 \pm 17.73$ \\
\hline Önem düzeyi (p) & $*$ & - \\
\hline $\begin{array}{ll}- & : \text { Önemsiz } \\
* & : \text { p }<0.05 \\
\text { ab } & \text { Aynı sütunda farklı harfleri } \\
& \text { önemlidir. }\end{array}$ & & indak \\
\hline
\end{tabular}

Levamizolun Karbakol ve Triklorfon İle Birlikte Etkisi: Levamizol $\left(5 \times 10^{-5} \mathrm{M}\right)$ ile 20 dak inkübasyon karbakolun $\mathrm{pD}_{2}$ değerini azaltmış $(\mathrm{p}<0.05) \mathrm{E}_{\max }$ değerini artırmıştır $(\mathrm{p}<0.05)$. Triklorfon ile inkübasyon, triklorfon ve levamizol ile inkübasyon ile karşılaştırılınca, triklorfon ve levamizol ile inkübasyonun $\mathrm{pD}_{2}$ değerinde azalma $(p<0.05)$ tespit edilirken, $E_{\max }$ değerinde istatistiksel olarak anlamlı bir fark bulunamadı (Tablo 5).

Levamizolun Karbakol ve Mekamilamin İle Birlikte Etkisi: Levamizol ile inkübasyon karbakolun $\mathrm{pD}_{2}$ değerini azaltırken $(\mathrm{p}<0.05), \quad \mathrm{E}_{\max }$ değerini artırdı $(p<0.05)$. Levamizol ile inkübasyon levamizol ve mekamilaminle inkübasyonla karşılaştırılınca levamizol ve mekamilamin inkübasyonunun $\mathrm{pD}_{2}$ değerinde azalma $(p<0.05), E_{\max }$ değerinde ise artma $(p<0.05)$ saptand (Tablo 6).

Kasılma Oluşturulan Dokularda Levamizolun Etkisi: Asetilkolinin $\mathrm{EC}_{85}\left(3 \times 10^{-5} \mathrm{M}\right)$ ile kasılma oluşturulmuş dokularda levamizol \% 17.25 \pm 1.78 kasılma oluşturdu (n: 8). Kasılma pik şeklinde olmadığından, Ak' $\operatorname{nin} \mathrm{EC}_{50}$ değeri ile $\left(10^{-5} \mathrm{M}\right)$ kasılma oluşturulan dokuların yanıtlarının $\mathrm{E}_{\max }(40.00 \pm 6.86)$ ile $\mathrm{Ak}^{\prime}$ nin $\mathrm{EC}_{50}$ değeri ile $\left(10^{-5} \mathrm{M}\right)$ kasılma oluşturulan ve üzerine levamizol $\left(10^{-8}\right.$ $\left.10^{-3} \mathrm{M}\right)$ uygulaması sonucunda alınan yanitların $E_{\max }$ (67.33 \pm 20.16$)$ karşılaştırıldı ve birikimli levamizol uygulamasinın yanitları istatistiksel olarak anlamlı artırdığ $1(\mathrm{p}<0.05)$ bulundu (n: 8). Karbakolun $\mathrm{EC}_{85}$ değeri ile $\left(1.7 \times 10^{-6} \mathrm{M}\right)$ kasılma oluşturulan dokularda (n: 7), levamizolun uygulanan en yüksek derişiminde bazal çizginin altına kadar düşen ani bir gevşemeye neden olduğu saptandı. Potasyum klorür $(80 \mathrm{mM})$ ile yapılan protokolde levamizol etkisiz bulundu.

Levamizolun Nikotin İle Birlikte Etkisi: Levamizol $\left(5 \times 10^{-5} \mathrm{M}\right)$ ile 20 dak inkübasyondan sonra tekrar nikotin $\left(10^{-4} \mathrm{M}\right)$ uygulandığında nikotinin tek başına oluşturduğu geçici kasılma oluşmadı (n: 7).

Levamizolun Betanekol ve Mekamilamin İle Birlikte Etkisi: Levamizol inkübasyonu betanekolun $\mathrm{pD}_{2}$ değerini azaltırken $(p<0.05), E_{\max }$ değerini değiştirmedi. Levamizol ve mekamilamin ile inkübasyonla levamizol inkübasyonunun $\mathrm{pD}_{2}$ ve $\mathrm{E}_{\max }$ değerleri arasında istatistiksel olarak anlamlı bir fark bulunmadı (Tablo 7).

\section{Tartışma ve Sonuç}

Levamizolun tek başına tavşan trakeası üzerine ne gevşeme ne de kasılma gibi bir etkisinin olmadığı saptand 1 (n:8). Köpek safen veninde (21), kobay bağırsağında (5) ve vas deferensinde (11) yapılan çalışmalarda da levamizolun etkisiz olduğu bildirilmiştir. Vanhoutte ve ark. (21), levamizolun spesifik olmayan bir şekilde ilaç reseptör ya da ilaç reseptör ilişkisine yakın bir şekilde düz kas hücrelerini kasmadan bir etki oluşturduğunu belirtmișlerdir. Çalışılan dokular farklı olmakla birlikte, sonuçlar, bu çalışmanın sonucuyla uyum içindedir.

$\mathrm{Bu}$ çalışmada levamizolun $\left(5 \times 10^{-5} \mathrm{M}\right) 20$ dak inkübasyonu, $\mathrm{Ak}^{\prime}$ nin $\mathrm{pD}_{2}$ değerlerini değiştirmezken, $\mathrm{E}_{\max }$ değerlerinde istatistiksel olarak anlamlı bir artış $(p<0,01)$ meydana geldi. Gulati ve ark. (11), levamizolun $\left(4 \times 10^{-5} \mathrm{M}\right) \mathrm{Ak}^{\prime}$ nin $\mathrm{E}_{\max }$ değerini anlamlı olarak arttırsa da, maksimal etkinliğin yarısını değiştirmediğini belirtmişlerdir. Araştırıcılar, bu etkinin kolinesteraz enzim etkinliğinin önlenmesine bağlı olarak gelişebileceğini belirtmişlerdir. Bu çalışmanın bulguları Gulati ve ark. (11) yapmış olduğu çalışmanın bulguları ile benzerdir.

Çalışmanın karbakol ile yapılan bölümünde, levamizol $\left(5 \times 10^{-5} \mathrm{M}\right)$ ile dokunun 20 dak inkübasyonu, karbakolun hem $\mathrm{pD}_{2}$ hem de $\mathrm{E}_{\max }$ değerlerini değiştirdiği görülmüştür (Tablo 5). İlacın reseptöre olan afinitesindeki azalma, kolinesteraz inhibitörlerinin neden olduğu muskarinik reseptörlerin "down regülasyonu" sonucu oluşan toleransa benzemektedir $(1,23)$. Ancak, Yang ve ark. (23) OF bileşiklerin muskarinik reseptörlerde yol açtığı azalmanın afinitede bir azalma yapmadığını, Adler ve ark (1) ise, köpek trakeasında OF bileşiklerin Ak yanıtlarını artırırken, karbakol yanıtlarını değiştirmediği- 
ni bildirmişlerdir. Söz konusu çalışmaların bulguları göz önüne alındığında levamizolun asetilkolinesteraz (AkE) etkinliğini önlediğini söylemek güçtür. Sonuçlardaki farklılık, deneylerde kullanılan hayvanlar arasındaki tür farklılığına da bağlanabilir. Levamizolun etkisi, belki de ortamdaki kalsiyum iyonlarını hücre içine akımı ile ilgilidir. Zira, Nauailhetas ve ark. (18), tavşan trakea düz kasında hücre içi kalsiyum depolarının rolünü araştırmışlar ve kalsiyumsuz çözelti ile inkübe edilen dokulardaki karbakol yanıtlarının azaldığını tespit etmişlerdir.

Levamizolun $\left(5 \times 10^{-5} \quad\right.$ M) dokuda 20 dak inkübasyonu, betanekolun $\mathrm{pD}_{2}$ değerini karbakolde olduğu gibi azalttı (Tablo 7). Afinitedeki bu değişiklik yine karbakoldeki gibi muskarinik reseptörlerin "down regülasyonuna” bağlanabilir. Buranakarl ve ark.' nın (4), sidik kesesinde yaptığı çalışmada, atropin, nifedipin varlığında ve kalsiyumsuz ortamda, betanekol yanıtları izometrik pikte azalma, maksimal derişimin yarı değerinde ise artma oluşturmuştur. Araştırıcılara göre "down regülasyonun" mekanizması kalsiyumunun düz kas hücrelerine akımı ile ilgilidir.

Triklorfon $10^{-4} \mathrm{M}$ derişimde, levamizolle birlikte kullanıldığında $\mathrm{E}_{\max }$ değerini anlamlı şekilde düşürdü (Tablo 4). Yani triklorfonun derişimi artıkça, levamizol triklorfonun meydana getirdiği kasılmayı azalttı. Aldabagh ve ark. (2), levamizol ile ön sağaltımın diklorvos ile meydana gelen zehirlenmeyi azalttığını göstermiştir; araştırmacılar bu durumu levamizolun AkE' yi dönüşümlü olarak inhibe etmesinden ileri gelebileceğini ya da diklorvosla levamizolun AkE' nin farklı bölgelerine bağlanarak, birbirlerinin etkilerini azalttıklarını ileri sürmüşlerdir; ancak bu iki hipotezin de mekanizmayı tam olarak aydınlatamadığını belirtmişlerdir.

Karbakolun $\mathrm{EC}_{85} \quad\left(1.7 \times 10^{-6} \mathrm{M}\right)$ ile kasilma oluşturulan dokuda levamizol $10^{-4} \mathrm{M}$ ve $10^{-3} \mathrm{M}$ derişimlerde kasılmayı inhibe ettiği gözlendi. $\mathrm{Ak} \mathrm{EC}_{85}$ $\left(3 \times 10^{-5} \mathrm{M}\right)$ ile kasılma oluşturulan dokularda ise kademeli olmasa da bir artış görülmüştür. Vanhoutte ve ark. (21), $5 \times 10^{-5} \mathrm{M}$ asetilkolin ile kasılma oluşturulan dokularda $\left(2 \times 10^{-6}-4 \times 10^{-5} \mathrm{M}\right)$ levamizolun kasılmaları belirgin şekilde artırmadığını ortaya koymuştur. Caposso ve ark. (5), levamizolun $20 \mu \mathrm{g} / \mathrm{ml}$ 'ye kadar $\mathrm{PGE}_{2}$ ile oluşturulan kasılmaları artırdığını, ancak daha yüksek derişimlerde kasılmaların ilaçtan etkilenmediğini ya da baskılandığını göstermişlerdir. Araştırıcılar etkinin sinir sonlarından Ak salınmasından ya da otonomik gangliyonların uyarılmasından kaynaklanmadığı yorumunu yapmışlardır.

Yapılan çalışmadan elde edilen sonuçlar levamizolun muskarinik agonist bir etki ile down regülasyona neden olup afiniteyi azalttığına işaret etmektedir. Ancak, burada gerçek bir muskarinik agonist etkiden söz etmekte güçtür; çünkü, levamizol muskarinik agonistlerin ortaya çıkardığı yanıtlara benzer bir etki ortaya çıkarmamaktadır. Levamizolun etkisinin, kalsiyumun hücre içine dönmesine ve hücre dışı sıvıdaki kalsiyum iyonlarını azaltarak karbakol ve betanekol yanıtlarını azaltmasından kaynaklanabileceği de düşünülmüştür. Triklorfon $\left(10^{-6} \mathrm{M}\right)$ ile yapılan deneylere göre levamizol ile triklorfonun birlikte kullanılmaması gerektiği söylenebilir, çünkü levamizol ve triklorfon birlikte Ak yanıtlarını çok daha fazla artırmışlardır. Çalışmanın verileri ayrıca, levamizol ile betanekol arasında yarışmalı bir antagonizma olduğunu gösterir niteliktedir. Yapılan çalışmada az da olsa levamizolun tavşan trakeası üzerine nikotinik etkilerinin olduğu tespit edilmiştir. Nikotinin sadece belli bir dozda yanıt oluşturduğu da dikkate alınırsa, nikotin cevabındaki kaybolmanın, levamizolun ilave bir etki ile reseptörleri duyarsızlaştırıcı etkisinden kaynaklanabileceği söylenebilir. Ancak levamizol ile zehirlenmelerde mekamilamin gibi gangliyon blokörünün yeterli olacağı söylenemez. Levamizolden kaynaklanan ölümlerin başlıca sebebi solunum yetmezliği olduğundan, gangliyon blokörünün yanı sıra atropin de kullanılmalıdır.

\section{Kaynaklar}

1. Adler M, Moore DH, Filbert MG (1992): Mechanism of soman-induced contractions in canine tracheal smooth muscle. Arch Toxicol, 66, 204-210.

2. Aldabagh II, Mohammad FK (1999): Reduction of dichlorvos induced toxicosis in rabbits by levamisole. Erişim: www.vef.hr/vetarhrv/69-1/aldabagh.htm. Erişim tarihi: 20.11 .2000

3. Atchison WD, Geary TG, Manning B, Vandewaa EA, Thompson DP (1992): Comparative neuromuscular blocking of levamisole and pyrantel-type antelmintics on rat and gastrointestinal nematode somatic muscle. Toxicol Appl Pharmacol, 112,133-143.

4. Buranakarl C, Kijtawoornnat A, Angkanaporn K, Komolvanich S, Bovee KC (2001): Effects of bethanecol on canine urinary bladder smooth muscle function. Res Vet Sci, 71, 175-181.

5. Caposso F, Moscolo N, Autore G (1982): Enhancement by levamisole of the contractions induced by prostaglandin $E_{2}$ in the guinea-pig isolated ileum. Prostaglandins, 23, 427-432.

6. Cook WO, Osweller GD, Walter H, Stahi HM (1985: Levamisole toxicosis in swine. Vet Hum Toxicol, 27, 388389.

7. Einstein R, Jones RS, Knifton A, Starmer, G.A. (1994): Principles of Veterinary Therapeutics. Longman Singapore Publishers Ltd. Singapore.

8. Eyre P (1970): Some pharmacodynamic effects of nematocides: methyridine, tetramisole and pyrantel. J Pharm Pharmac, 22, 26-36.

9. Ford EJH, Abdelsalam, EB (1983): Combined effect of levamisole and organophosphorus compounds on calves . Vet Rec, 112, 106.

10. Ford EJH, Evans AB (1987): Combined effect of slow release levamizole on prolate on acethylcholine activity in cattle. Vet Rec, 120, 579-580 
11. Gulati OD, Hemevathi K, Joshi DP (1985): Interactions of levamizole with some autonomic drugs on guinea pig vas deferens. J Auton Pharmac, 5, 19-25.

12. Hsu WH (1980): Toxicity and drug interactions of levamisole. JAVMA, 176, 1166-1169.

13. Hsu WH (1981): Drug interactions of levamizole with pyrantel tartrate and dichlorvos in pigs. Am J Vet Res, 42, 1912-1914.

14. Hulsmann AR, De Jongste J C (1993). Studies of human airways in vitro: a review of the methodology. $\mathrm{J} \mathrm{P} \mathrm{M}, \mathbf{3 0}$, 117-132.

15. Kaya S (2000): Antelmintikler. 421-477. In: S. Kaya; İ. Pirinçi; A, Bilgili (Ed) Veteriner Uygulamalı Farmakoloji Cilt II. Medisan. Ankara.

16. Kayaalp SO (2000): Rasyonel Tedavi Yönünden Tibbi Farmakoloji. 1. Cilt. 9. Baskı. Hacettepe Taş Kitapçılık Ltd Şti. Ankara.

17. Kurtdede A, Baydan E, Börkü MK, Kalınbacak A. (1992): Köpeklerde tetramizol ve triklorfonun kan parametrelerine etkileri. Ankara Üniv Vet Fak Derg, 39, 168172

18. Nauailhetas VLA, Lodge, NJ, Twort CHC, Van Breeman C. (1998): The intracellular calcium stores in the rabbit trachealis. Eur J Pharmacol, 157, 165-172
19. Shah KK, Gulati OD, Hememavathi KG (1986): Investigation of some effects of levamisole on dog blood pressure. Int J Physiol Pharmacol, 30, 55-62.

20. Şanlı Y (1999): Veteriner Klinik Farmakoloji ve İlaçla Sağaltım İlkeleri. Özkan Matbaacılık Ankara.

21. Vanhoutte PM, Vannueten JM, Verbeuren TJ, Laduron PM (1977): Differential effects of the isomers of tetramisole on adrenergic neurotransmission in cutaneous veins of dog. J Pharmacol Exp Ther, 200, 127-140.

22. WHO(2003a).Seri:27.Levamisole.Erişim: http://www.inchem.org/documents/jecfa/jecmono/v27je04. htm Erişim tarihi: 26.02.2003

23. Yang CM, Dwyer TM, Farley JM (1991): Muscarinic reseptors and mukus secretion in swine tracheal epithelium: effects of subacute organophosphate treatment. Fundam Appl Toxicol, 17, 34-42

Geliş tarihi: 07.04.2004 / Kabul tarihi: 12.04.2004

\section{Yazışma adresi:}

Dr. Ebru Yıldırım

Kırıkkale Üniversitesi Veteriner Fakütesi

Farmakoloji ve Toksikoloji Anabilim Dalı

Yahşihan/Kırıkkale

e-mail:ebruustuner@hotmail.com 